Walther Hüls Güido, Wolfgang Lanser, Stefan Petersen, Felix Ziegler

\title{
Performance of absorption chillers in field tests
}

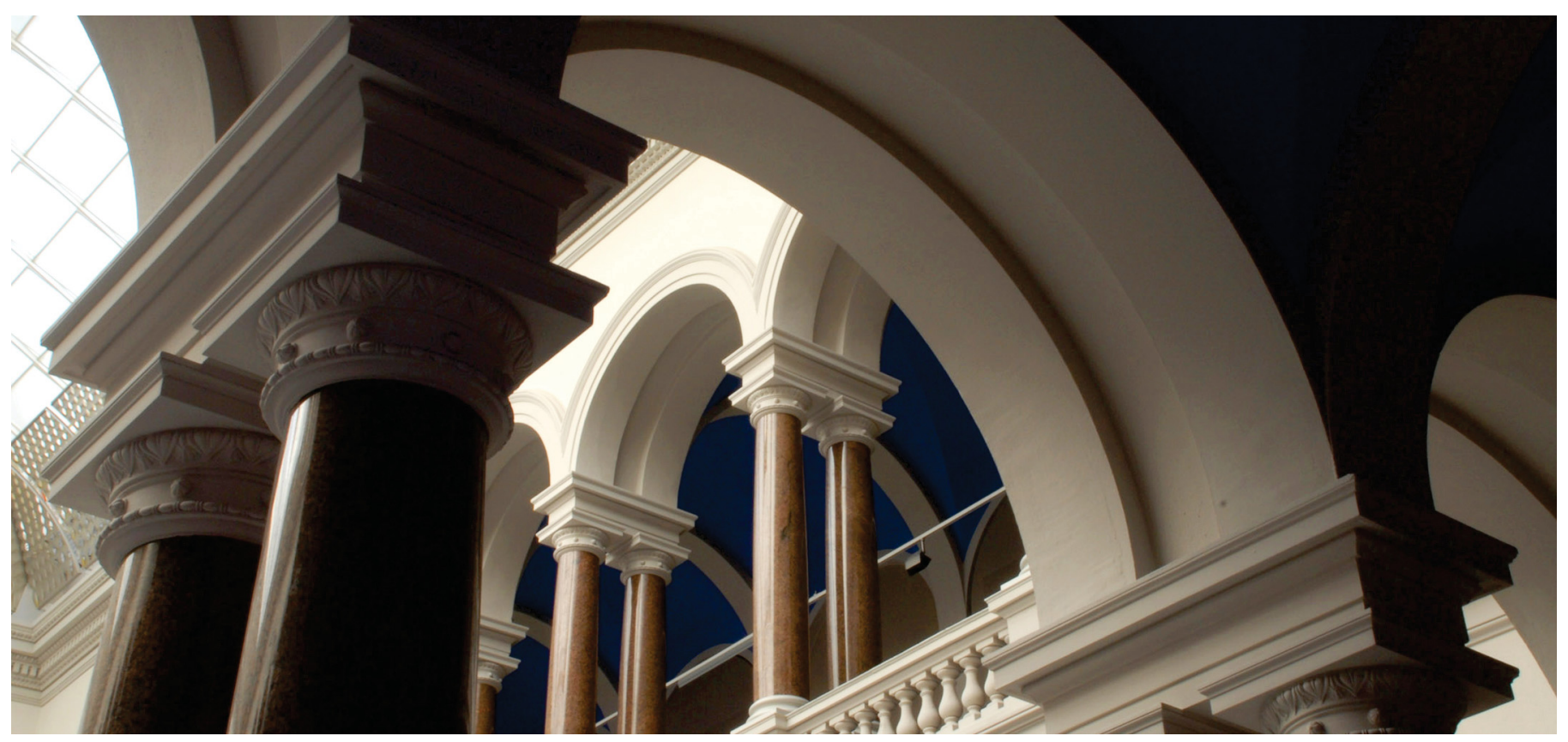

Hüls Güido, W., Lanser, W., Petersen, S., \& Ziegler, F. (2018). Performance of absorption chillers in field tests. Applied Thermal Engineering, 134, 353-359.

https://doi.org/10.1016/j.applthermaleng.2018.02.013 


\title{
Performance of absorption chillers in field tests
}

\author{
Walther Hüls Güido*, Wolfgang Lanser, Stefan Petersen, and Felix Ziegler \\ Technische Universität Berlin, Institute of Energy Engineering, KT2 \\ Marchstraße 18, D-10587 Berlin, Germany \\ *Corresponding author: waltherh@mailbox.tu-berlin.de
}

Keywords: system efficiency, trigeneration, combined cooling, heat and power CCHP, solar cooling, dry cooling towers, thermally driven cooling

\begin{abstract}
Absorption chillers can use waste heat, solar heat, or excess heat by cogeneration facilities to supply chilled water. Therefore, absorption chillers are important components for polygeneration, which can improve plant utilization and efficiency of the overall energy supply system.
\end{abstract}

Currently, 27 new small and medium-scale ${ }^{1}$ absorption chillers with high efficiency in fulland part-load as well as low specific size and weight are the focus of two research projects sponsored by German Federal Ministries. The chillers are located in 20 different sites, four of them in Jordan and the rest in Germany. The main objective of these projects is to enhance trigeneration and solar cooling system efficiency.

The Jordan projects and more than $70 \%$ of the German installations use dry cooling towers. Combined heat and power (CHP) plants or district heating grids provide the driving heat for regeneration at the German installations. Solar thermal collectors drive one German and all Jordan installations.

Within the projects, the chillers are provided with an intelligent control algorithm that allows achieving several objectives at the same time. One of the objectives, of course, is to match the desired chilled water temperature as well as the cooling capacity. Another objective is, for instance, to fit the hot water outlet temperature. This is commonly essential in cogeneration to avoid emergency shutdowns of the CHP engine. The field operation shows that the deviation of said temperatures from the set point is usually less than $\pm 0.5 \mathrm{~K}$ in operation. In those operational hours in which the temperatures of the heat source or heat sink do not allow to reach all objectives, a set of hierarchical aims can be established within the algorithm so that the chiller can be controlled to match its prioritized objectives.

Furthermore, the designed absorption chiller performs dynamically and autonomously in a very large range of temperatures and flow rates. These can vary from $20 \%$ up to $150 \%$ of nominal conditions. This flexibility can be used to achieve up to $80 \%$ savings of electrical power consumption using speed-controlled pumps in part load conditions.

In contrast to the common opinion that small and medium-scale absorption chillers are not competitive as compared to compression chillers, this paper shows applications in which absorption chillers are advantageous because of synergies with and multiple benefits within the rest of the energy supply system.

\footnotetext{
${ }^{1} 30$ to $160 \mathrm{~kW}$ cooling capacity
} 


\section{Introduction}

Although the demand for space cooling is increasing globally [1], it is an aim (and for sustainable energy use it is even compulsory) to decrease energy consumption for cooling. Compression chiller technology (which of course is improving over the years) dominates small to medium-scale installations (cooling capacity about $150 \mathrm{~kW}$ ). Improving electrically driven solutions and basing them on alternative, green energies may be not enough to reach the sustainability goals, and may be economically unfeasible. Results of the Summerheat project [2] show that using large-scale absorption chillers in district cooling networks is energy efficient and reduces the electricity consumption. However, in terms of cost effectiveness small to medium scale absorption chillers are reported to be inappropriate up to now [2].

In the recent years, TU Berlin has been leading several projects to develop single effect water/lithium bromide absorption chillers within the said range of capacity with a smaller specific size and weight [3] to improve the cost-effectiveness. Based on one basic design, two differently sized absorption chillers have been designed, called Bee and Bumblebee (50 and $160 \mathrm{~kW}$ nominal cooling capacity, see Table 1). A third one, the Hornet with $500 \mathrm{~kW}$ nominal capacity, was just recently developed and therefore has not yet been part of the presented projects. The company W. Bälz \& Sohn GmbH \& Co. now markets the absorption chillers.

\begin{tabular}{|c|c|c|c|c|c|}
\hline \multicolumn{2}{|c|}{ Absorption chiller (water/lithium bromide) } & type & bee & $\begin{array}{c}\text { bumble- } \\
\text { bee }\end{array}$ & \multirow{2}{*}{$\begin{array}{c}\text { example for a } \\
\text { specific } \\
\text { location } \\
\text { (bumblebee) }\end{array}$} \\
\hline & Description & Units & \multicolumn{2}{|c|}{ nominal conditions } & \\
\hline$t_{2 D i}$ & Hot water inlet temperature & ${ }^{\circ} \mathrm{C}$ & \multicolumn{2}{|c|}{90} & 85 \\
\hline $\mathrm{t}_{2 \mathrm{Do}}$ & Hot water outlet temperature & ${ }^{\circ} \mathrm{C}$ & \multicolumn{2}{|c|}{70} & 70 \\
\hline $\mathrm{V}_{2 \mathrm{Dx}}$ & Hot water volumetric flowrate & $\mathrm{m}^{3} / \mathrm{h}$ & 3.2 & 10 & 6 \\
\hline $\mathrm{Q}_{2 \mathrm{Dx}}$ & Driving heat & $\mathrm{kW}_{\text {th }}$ & 63 & 200 & 105 \\
\hline $\mathrm{t}_{1 \mathrm{Ai}}$ & Cooling water inlet temperature & ${ }^{\circ} \mathrm{C}$ & \multicolumn{2}{|c|}{30} & 27 \\
\hline $\mathrm{V}_{\mathrm{AC} 1}$ & Cooling water volumetric flowrate & $\mathrm{m}^{3} / \mathrm{h}$ & 14 & 46 & 39 \\
\hline $\mathrm{Q}_{\mathrm{AC} 1}$ & Reject heat & $\mathrm{kW}_{\text {th }}$ & 113 & 360 & 185 \\
\hline $\mathrm{t}_{\mathrm{OEo}}$ & Chilled water outlet temperature & ${ }^{\circ} \mathrm{C}$ & \multicolumn{2}{|c|}{16} & 6 \\
\hline $\mathrm{V}_{0 \mathrm{Ex}}$ & Chilled water volumetric flowrate & $\mathrm{m}^{3} / \mathrm{h}$ & 8.6 & 28 & 14 \\
\hline $\mathrm{Q}_{0 \mathrm{Ex}}$ & Cooling capacity & $\mathrm{kW}_{\text {th }}$ & 50 & 160 & 80 \\
\hline $\mathrm{COP}_{\text {th }}$ & Thermal coefficient of performance & $\mathrm{kW}_{\text {th }} / \mathrm{kW}_{\text {th }}$ & \multicolumn{2}{|c|}{0.79} & 0.74 \\
\hline $\mathrm{COP}_{\mathrm{el}}$ & Electric coefficient of performance & $\mathrm{kW}_{\text {th }} / \mathrm{kW}_{\mathrm{el}}$ & \multicolumn{2}{|c|}{20} & \\
\hline
\end{tabular}

Table 1. Absorption chiller specifications in nominal conditions

A large fraction of the investment cost in all cooling units originates from heat exchangers. In this respect, heat driven cooling technologies will always have a drawback. Therefore, there is no point in comparing absorption and compression chillers without discussing availability, price, and primary energy demand, which is different in every national and even local energy supply system. Fully standardized solutions will only reach part of the market. Hence, the economy of scale will only be strong when there is a technology that has a flexible operation and control adaptability to as much requirements as possible. A step towards these goals is reported in this paper showing at the same time an overview of the project scope and results.

Focusing on the driving heat circuit, this paper gives a brief description of the control methodology that allows the absorption chiller to perform flexibly in different operating 
conditions. Especially the operation with three types of driving heat (solar heat, centralized co-generated and decentralized co-generated heat) is discussed. Key data show how the absorption chiller performs in the given conditions. Finally, the paper reports first results to decrease the auxiliary electricity consumption.

In order not to overload the paper, only those details of the installations, which are necessary to understand the control issues, are provided here. Further information will be available in future papers and the final project reports.

\section{Load control in different applications}

\subsection{Description of the control system}

To work autonomously, reliably and endurably in the different operating modes, the control algorithms within the field tests run with an industrial programmable controller. The routines can be described by dividing them into two main independent tasks: process control and load control. The process control ensures safe operation. When exceeding preset limits, the process control first takes concrete actions to return to normal operation. If the problems persist and there is no actor to react appropriately, the absorption chiller will be shut down. This, however, is not topic if the paper at hand.

The load control is based on the steady state characteristic equation [4] using constant parameters (which are based on measurements in a test rig) characteristic to the designed chillers. The load control algorithms describe the process state by using external temperatures and flow rates, and determine two set points for the inlet temperatures of hot and cooling water (reject heat). These two set points are two degrees of freedom, which are used to adjust to one or more control objectives. They are conveyed to the PID-controllers of the valves and pumps. Additionally, to compensate for inaccuracies in the characteristic equation, thermophysical parameters and heat flows are compared to measurements in order to make online corrections in the model working as an observer in terms of Lueneberger [5].

\subsection{Solar thermal cooling}

In regions like Jordan, where insolation is high, it is meaningful to use solar energy, either as electricity or as heat. Thermal collectors are interesting when a significant heat demand exists. However, this demand is never steady over the time and often emergency coolers have to be installed to release excessive heat during periods of high insolation and no complementary demand; otherwise, the high temperatures can damage the collector or the working fluid. This situation is convenient for cooling with absorption chillers as the cooling demand increases simultaneously with insolation. However, as another effect of high insolation the potential of the chillers to reject heat to the ambient is impeded. This commonly requires evaporative- or wet cooling towers, which means a drawback in locations with water scarcity.

In the Jordan installations, the chillers and their controls handle these extreme conditions properly even with dry cooling towers. In order to show this, in Figure 1 the temperatures of the hot water (desorber inlet and outlet), cooling water (absorber inlet) and produced chilled water (evaporator outlet) are plotted in the top graph for one day in August. All sensors are located in thermowells near the chiller. The evaporator produces $10^{\circ} \mathrm{C}$ all day long despite the ambient conditions, as this is the priority set in the control. The chiller starts operation at around $7 \mathrm{a} . \mathrm{m}$. with a low driving heat temperature of approximately $50-55^{\circ} \mathrm{C}$. At noon, it 
operates at about $100^{\circ} \mathrm{C}$ with the reject heat at a temperature of almost $40^{\circ} \mathrm{C}$. The cooling power is almost constant at $50-55 \mathrm{~kW}$ (see bottom graph), while the driving heat flow is larger in the beginning of the day than in the afternoon. The reason is the non-steady operation: in the morning, driving heat is used to warm up the installation additionally to the cold production. In the afternoon, when the temperatures are slowly falling again, the amount of driving heat is less than before noon, because the chiller also cools down a bit and uses its own heat capacity for desorbing. Consequently, the momentary $\mathrm{COP}_{\text {th }}{ }^{2}$ is better in the afternoon than in the morning.

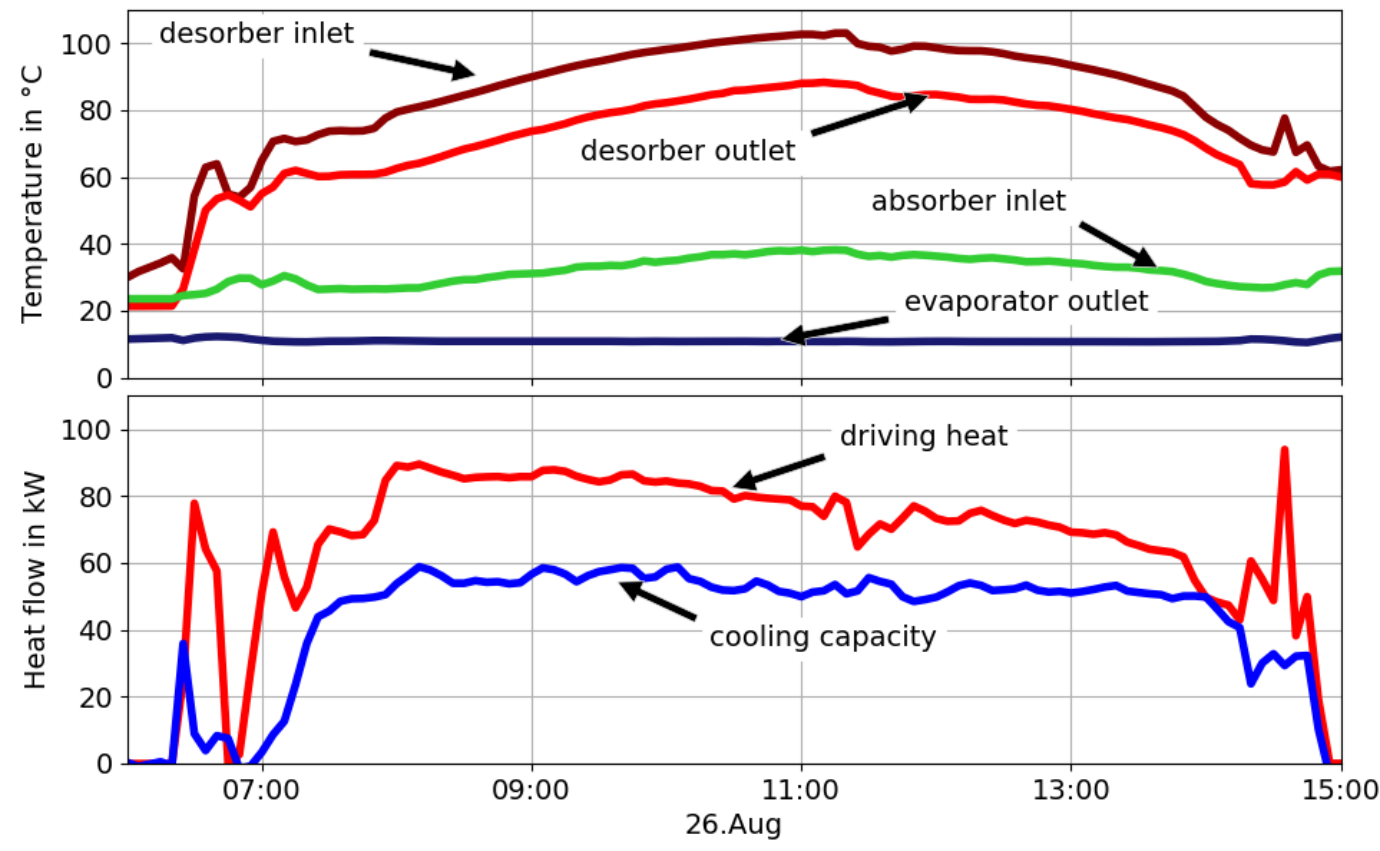

Figure 1. Absorption chiller operating in extreme conditions in Jordan (Timestamp is in UTC. Jordan current time $=\mathbf{U T C}+3$ in August)

\subsection{Decentralized CCHP - Using excess heat from power generation for cooling}

Today, almost all available water/lithium absorption chillers have restricted operational conditions. Exceeding the nominal range of flow rates or temperatures leads to emergency shutdown of the chillers in order to avoid freezing of the evaporator and crystallization of the solution at high salt content. This limitation, however, is detrimental for working with other restricted technologies, e.g. CCHP (combined cooling, heating, and power) with CHP engines, where further limitations occur due to the restriction of temperature in the cooling water circuit of the CHP plant. For CHP plants, it is essential to keep the hot water outlet temperature of the absorption chiller's desorber below CHP-manufacturer specification limits in order to avoid emergency shutdown of the CHP engine, resulting in economic loss or deficit of heat and electric power supplies.

Usually, periodical fluctuations of the cooling load or ambient temperature changes amount and temperature of the driving heat flow to the chiller. If waste heat of a CHP-engine drives

\footnotetext{
${ }^{2}$ The thermal coefficient of performance $\mathrm{COP}_{\text {th }}$ is defined as the ratio between heat flow of evaporator and heat flow of desorber. This definition, however, is only valid in a strict sense for steady state operation. As the shown operation is never stationary, we do not show the COP th in the figure.
} 
the absorption chiller, these fluctuations affect the performance of the CHP. By operating in CHP-specific mode, the absorption chiller can compensate those fluctuations. In this operation mode, the control algorithm of the absorption chiller has been configured to ensure that the hot water outlet temperature of the desorber amounts to a temperature of $63^{\circ} \mathrm{C}$ (see figure 2), although the operation is not at all steady. This aim has the highest priority in this location and can be achieved within a range of $\pm 0.5 \mathrm{~K}$ as shown in Figure 3 .

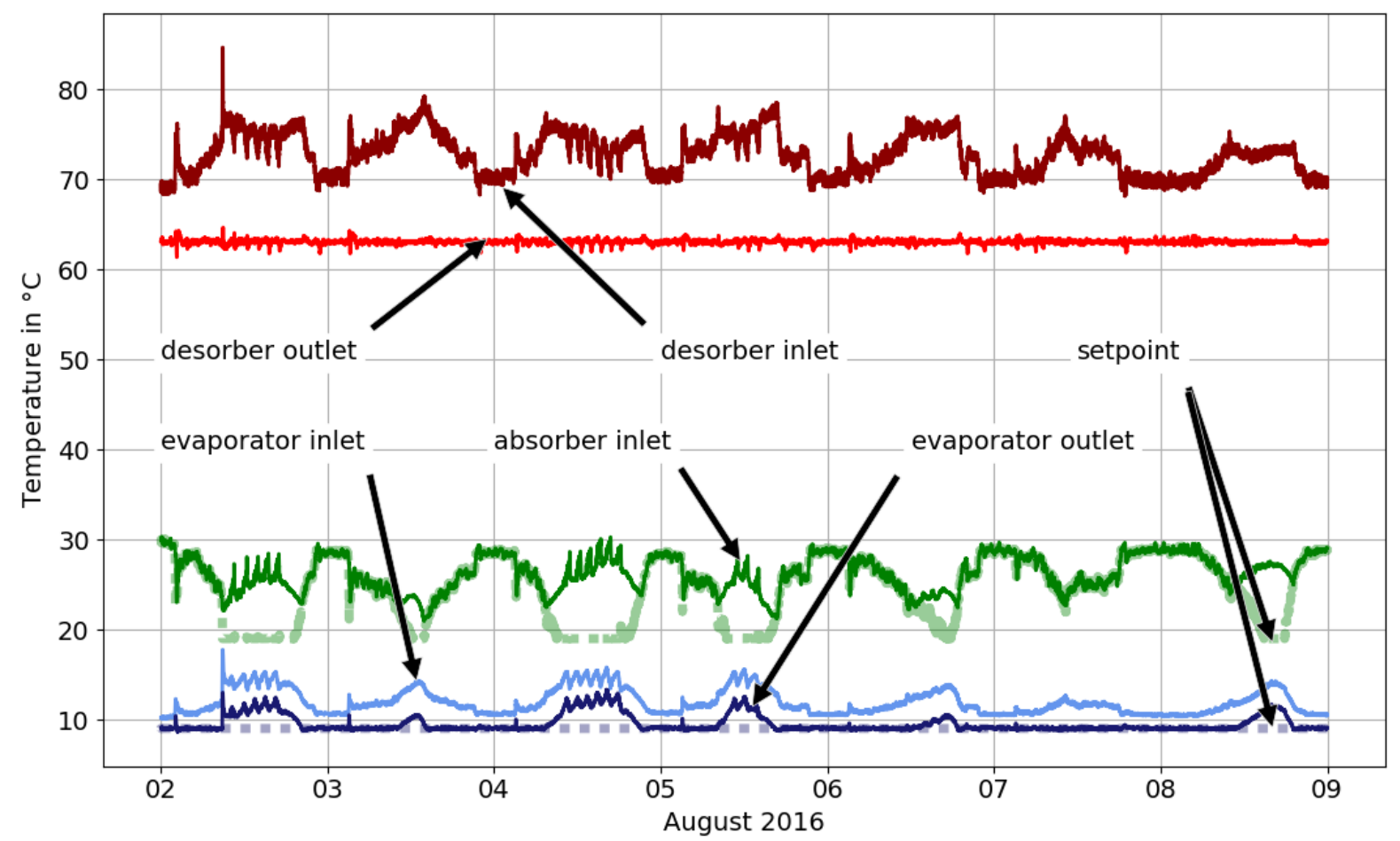

Figure 2. Matching challenges of set values in temperature return line (driving heat)

Figure 2 shows the controlled chiller operation over about one week. The evaporator outlet temperature set point (dotted faint line) is $9^{\circ} \mathrm{C}$ constant. The evaporator inlet temperature shows strong long wave and short wave oscillations, which are due to the varying cooling demand and the control characteristics of the customer. In order to compensate these, i.e. in order to hold the desorber outlet constant (first priority) and reach the set evaporator outlet temperature (second priority), the controller determines a required generator inlet temperature and an absorber inlet temperature set point (dotted faint line). Both, desorber and absorber inlet temperatures are the control variables. Increasing the desorber temperature and decreasing the absorber temperature results in an increase of cooling power. Thus, these two temperatures usually evolve in a symmetrical way in order to meet the objectives. If the boundary conditions (desorber- and absorber inlet temperature) are not restricted, both objectives are met. This is possible usually at night, but also on 7 August during the whole day. Nevertheless, there are instances (the first one on 2 August) when the absorber inlet does not achieve the desired set temperature because the latter is lower than the ambient temperature. Therefore, the absorber inlet follows the ambient temperature instead of the set temperature, which is required to meet both objectives. Now, the chilled water temperature set point could be reached with an increased desorber inlet temperature. Then, however, the desorber outlet temperature would rise also which is to be avoided in this operating mode with highest priority. Consequently, the chilled water set point is not reached because it is of second priority only. 


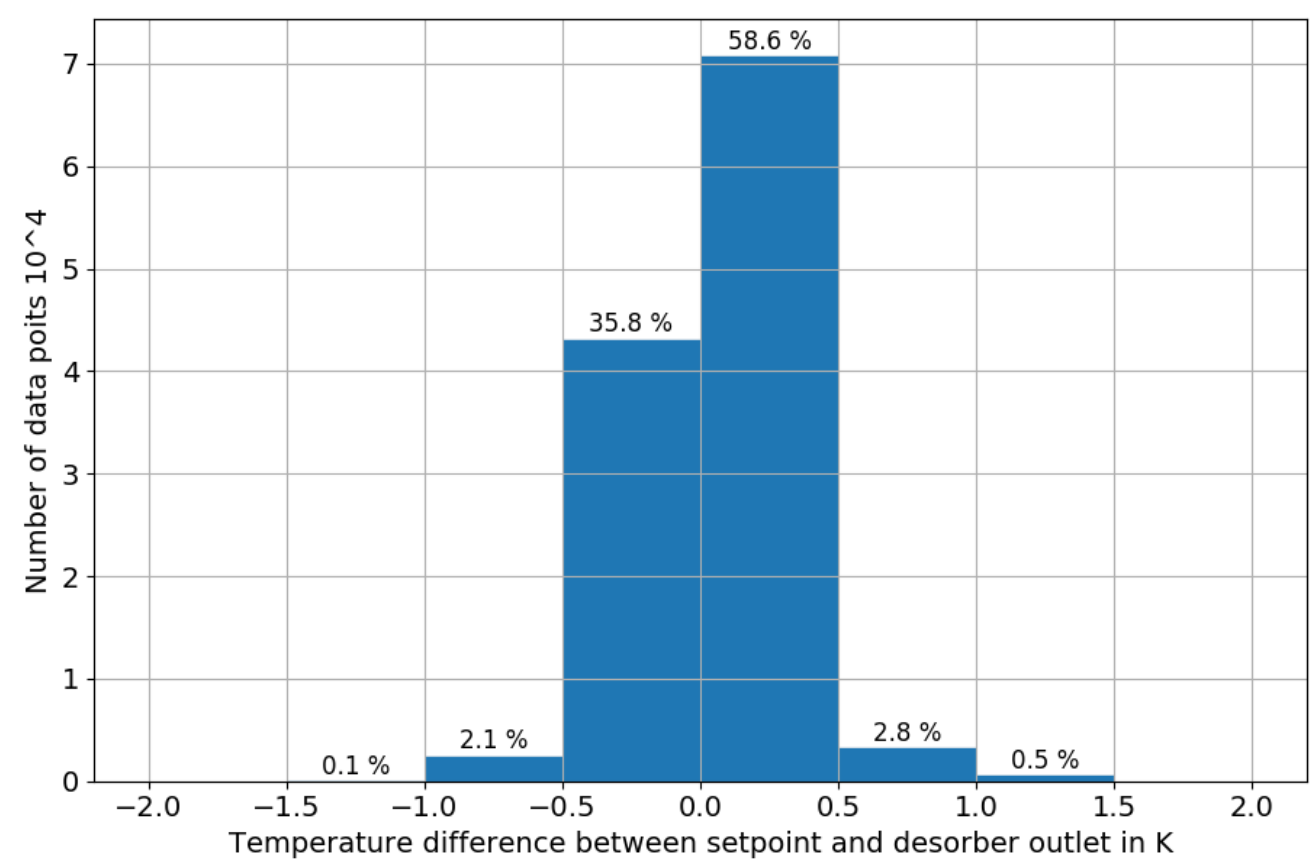

Figure 3. Distribution of the temperature deviation of the desorber outlet from the set point. 58.6\% of the measured data points, when the absorption chiller was in operation, have a deviation of 0 to $0.5 \mathrm{~K}$ from the set point.

In most space cooling installations, this will be tolerable as the building mass is buffering fluctuations. In other cases (like the one reported here), additional chillers will cover the residual cooling load of the consumer.

\subsection{Centralized CCHP - Using the district heating grid for cooling}

Centralized power plants that supply district heating networks with heat by steam extraction are known since a long time. In Central Europe, heating in winter season dominates the operation of the district heating networks. The typical return line temperatures in the district heat network of approx. $50^{\circ} \mathrm{C}$ match the needs of the power station: the lower the return temperatures are, the smaller the reduction in electricity output due to steam extraction will be.

In summer, the load of the heating network typically is only about $20 \%$ of winter load. Moreover, the tap water stations, which are connected to the district heating grids and often dominate the load in summer, bring forth a temperature of about to $70^{\circ} \mathrm{C}$ in the return line, which results in a larger power loss factor in the power plant. Sorption chillers, which can operate with driving heat with return temperatures significantly below $70^{\circ} \mathrm{C}$, are very advantageous because they cool down the return line and at the same time equilibrate the load between winter and summer.

Standard installations of absorption chillers in district heating networks and most of the field test installations of the reported project use the supply line of the grid to deliver heat of $75^{\circ} \mathrm{C}$ to $90^{\circ} \mathrm{C}$ as driving heat source. The return temperature to the grid (chiller desorber outlet) is held below $63^{\circ} \mathrm{C}$ in the installations reported on here [6]. One of the installations, however, located in the town of Kassel, is even using the grid return line as heat supply for the desorber.

The upper graph of Figure 4 is a temperature duration curve of the grid return line. The graph shows that in more than $6000 \mathrm{~h}$ of the year the grid return temperature is below $60^{\circ} \mathrm{C}$. This is 
still enough to operate the absorption chiller. The lower graph of figure 4 shows a desorber inlet temperature lower than $60^{\circ} \mathrm{C}$ in $5000 \mathrm{~h}$ of the year. The desorber outlet temperature, which goes to the grid return line, is below $50^{\circ} \mathrm{C}$ in approximately half of the operating time and below $60^{\circ} \mathrm{C}$ in more than $7500 \mathrm{~h}$. The required desorber inlet temperature to match the cooling load in approximately $94 \%$ of the time is lower than the available temperature in the return line of the district heating network ${ }^{3}$. This shows the potential of the system to cool down the return line temperature and convert heat from the grid return line to cold. In cases of high loads, of course, the feed line of the district heating network is used to deliver higher temperatures to the desorber - but this happened only in $6 \%$ of the time of operation.

Other concepts to cool down the return line from district heating grids are part of the ongoing tasks in the project. One idea is to use the absorption chiller in winter as a heat pump, driven by the district heat supply line and using the return line as low temperature heat source in the evaporator. The return line temperature shall decrease by $20-40 \mathrm{~K}$ compared to the state of the art. Less pump effort in the network, the potential to connect $20 \%$ more customers to the grid and decreasing heat losses will lead to benefits for both the energy supplier and the environment.
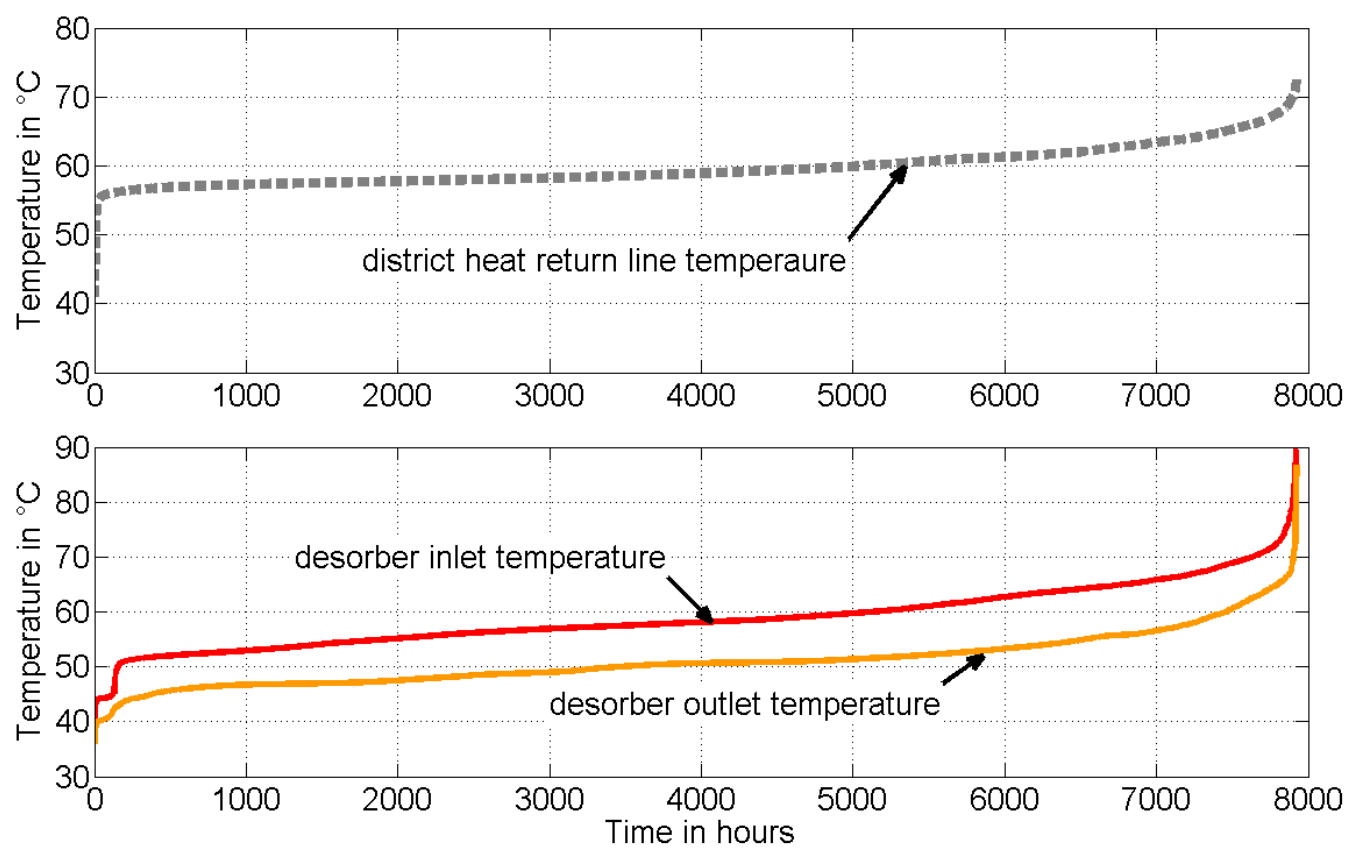

Figure 4. Temperature duration curve of (upper diagram) the district heat return line and (lower diagram) the driving temperatures of the absorption chiller [7]

\footnotetext{
${ }^{3}$ This cannot be seen in Figure 4 directly because individual ordered duration lines are shown. The time bins of the abscissa are not identical in upper and lower graph.
} 


\section{Electricity consumption of peripheral components.}

Despite the high thermal efficiency of the absorption chillers, improvements can be achieved especially in the electrical efficiency, $\mathrm{COP}_{\mathrm{el}}{ }^{4}$. It depends on the performance of peripheral components like pumps or reject heat devices. Measures have been taken to achieve improved operation with those peripheral components. Actually, the $\mathrm{COP}_{\mathrm{el}}$ is 20-50 $\mathrm{kW}_{\text {th }} / \mathrm{kW}_{\text {el }}$ without taking the cooling tower in consideration. The electrical efficiency with cooling tower lays in the range of about $5-20 \mathrm{~kW}$ th $/ \mathrm{kW}_{\mathrm{el}}$ and therefore is still a challenge, as $20 \mathrm{~kW}$ th $/ \mathrm{kW}_{\mathrm{el}}$ is a target value pursued in the project.

Actual efforts concentrate in the following two issues: operation with dynamically controlled volumetric flow rates and operation of clusters of absorption chillers.

\subsection{Operation with dynamic control of volumetric flow rates:}

The designed operating point in most installations is based on extreme conditions and considers the maximum cooling load in order to cover and ensure at any time the cooling demand. The ESEER (European standard energy efficiency ratio) considers 3\% of operation time at $100 \%$ load; hence, $97 \%$ of operation time not only the chiller itself but also the whole system will be in part load. As the typical operating conditions are much less severe than $100 \%$ load, this leads to a permanent drop in efficiency or excess consumption of auxiliary energy if no counter-measures are taken. High external volumetric flow rates, for example, cause unnecessary electricity consumption and additionally can even decrease the performance of the chiller by mixing down the evaporator inlet temperature when the volumetric flow rates of chiller and consumer differ. Therefore, matching the chilled water flow rates of the absorption chiller and the consumer can improve the efficiency.

Unfortunately, most chiller manufacturers do not account for changing external volumetric flow rates because this will affect transfer coefficients, fouling, and corrosion. Within the research project, however, a variation of the flow rate over the entire range of possible speed control of the chilled water pump led to the conclusion that varying of the flow rate causes no damage but provides energy savings and sometimes even efficiency improvement for the technology.

In Figure 5 experimental data are shown. The chilled water volumetric flow rate first was fixed to $25 \mathrm{~m}^{3} / \mathrm{h}$ (blue triangles), thus the electricity consumption of the chilled water pump was almost constant around $1 \mathrm{~kW}$ el. While using flexible speed control and forcing the volumetric flow rate set value in accordance to consumer's flow rate (green dots), the flow rate varied from one to $1 / 3$ of the fixed volumetric flow rate. The absorption chiller covered the cooling demand after the pump speed control has been implemented as well as it did before. However, the power consumption of the pump decreased in every situation except full capacity. At low cooling demand (about $40 \mathrm{~kW}$ ), the electricity consumption dropped down to $10 \%$ as compared to constant volumetric flow rate. Overall, the pump speed control reaches savings of about $70-80 \%$ of the electrical consumption due to the large number of operating hours with reduced load.

\footnotetext{
${ }^{4}$ The electrical coefficient of performance $\mathrm{COP}_{\mathrm{el}}$ is defined as the ratio between heat flow of evaporator and the amount of electrical energy of the peripheral components related to the absorption chiller.
} 


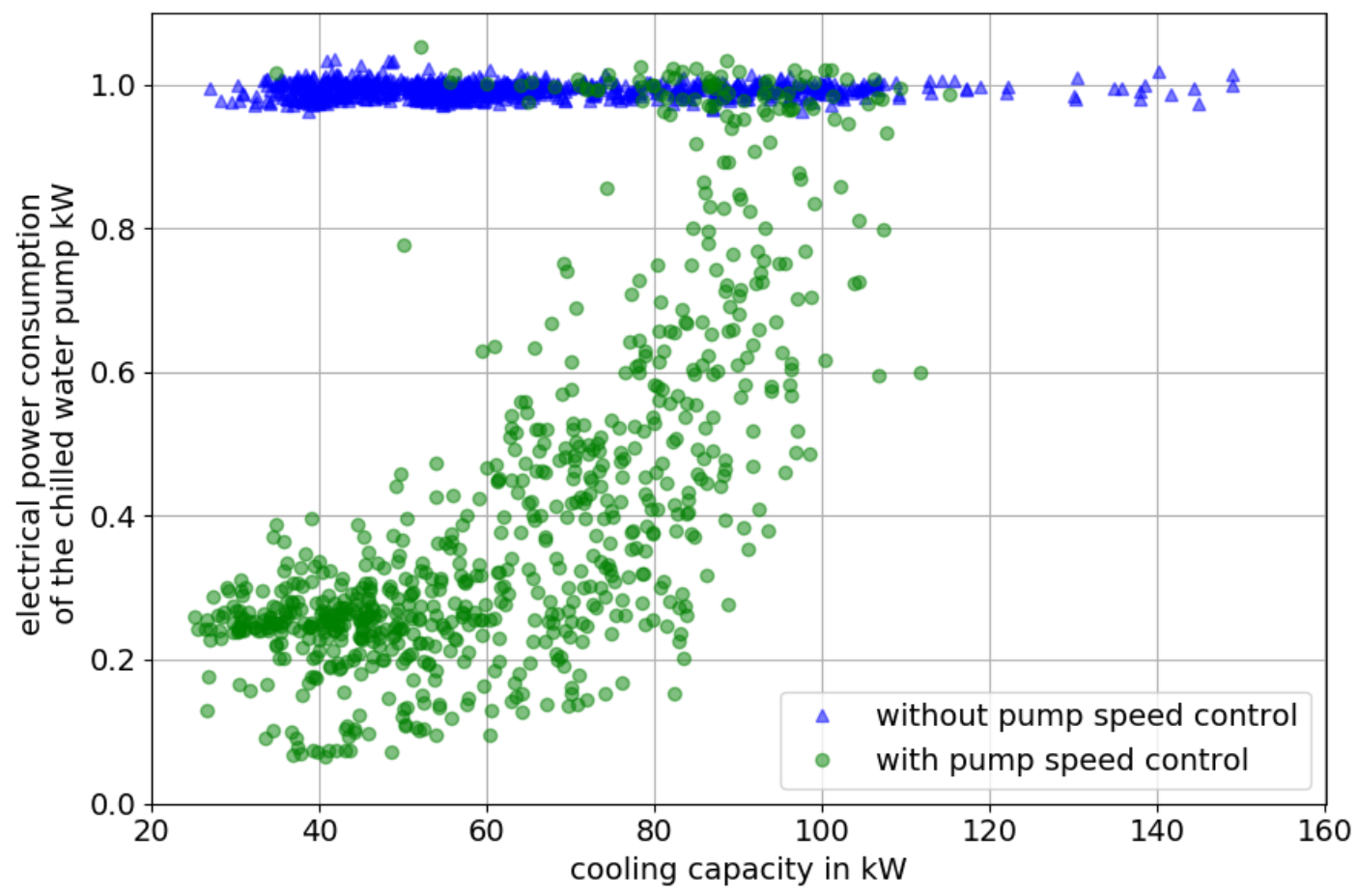

Figure 5. Comparison of electricity demand of chilled water pump modes - fix and variable set points

Further steps will be taken soon, transferring the same idea to the cooling water and hot water pumps, and to the cooling tower. First estimations promise that the savings are even larger than for the chilled water pump.

\subsection{Operation of clusters of absorption chillers:}

Some of the locations have a larger cooling demand than one chiller can provide. Therefore, a cluster of absorption chillers came into consideration. One location with three bumblebee absorption units is situated in Karlsruhe. Depending on the load condition, these three absorption chillers can provide an annual share of $2 / 3$ of the overall demand.

The monitoring data of the operation period from 2016 show a decrease of the load down to $50 \mathrm{~kW}$, especially at night, in spring and fall. The load is plotted against the ambient temperature (black dashed line) in figure 6 . In addition to the cooling demand, the theoretical cold production of the three absorption chillers (solid lines) as a function of the ambient temperature is plotted. For loads below $70 \mathrm{~kW}$ only one chiller is needed, two absorption chillers will be able to cover the load until $18^{\circ} \mathrm{C}$, and above that temperature three absorption chillers should work.

It is assumed here for simplicity that the fan of the cooling tower is controlled in such a way that the temperature of the cooling water inlet to the absorber is $8 \mathrm{~K}$ higher than the ambient temperature, with the purpose to operate the fans with low energy consumption. To cover the load above $19^{\circ} \mathrm{C}$ (intersection of three chillers and cooling load) this temperature difference has to be reduced which is possible only when the cooling tower fan speed is increased (not shown in the figure). This, of course, will increase the electrical consumption. 


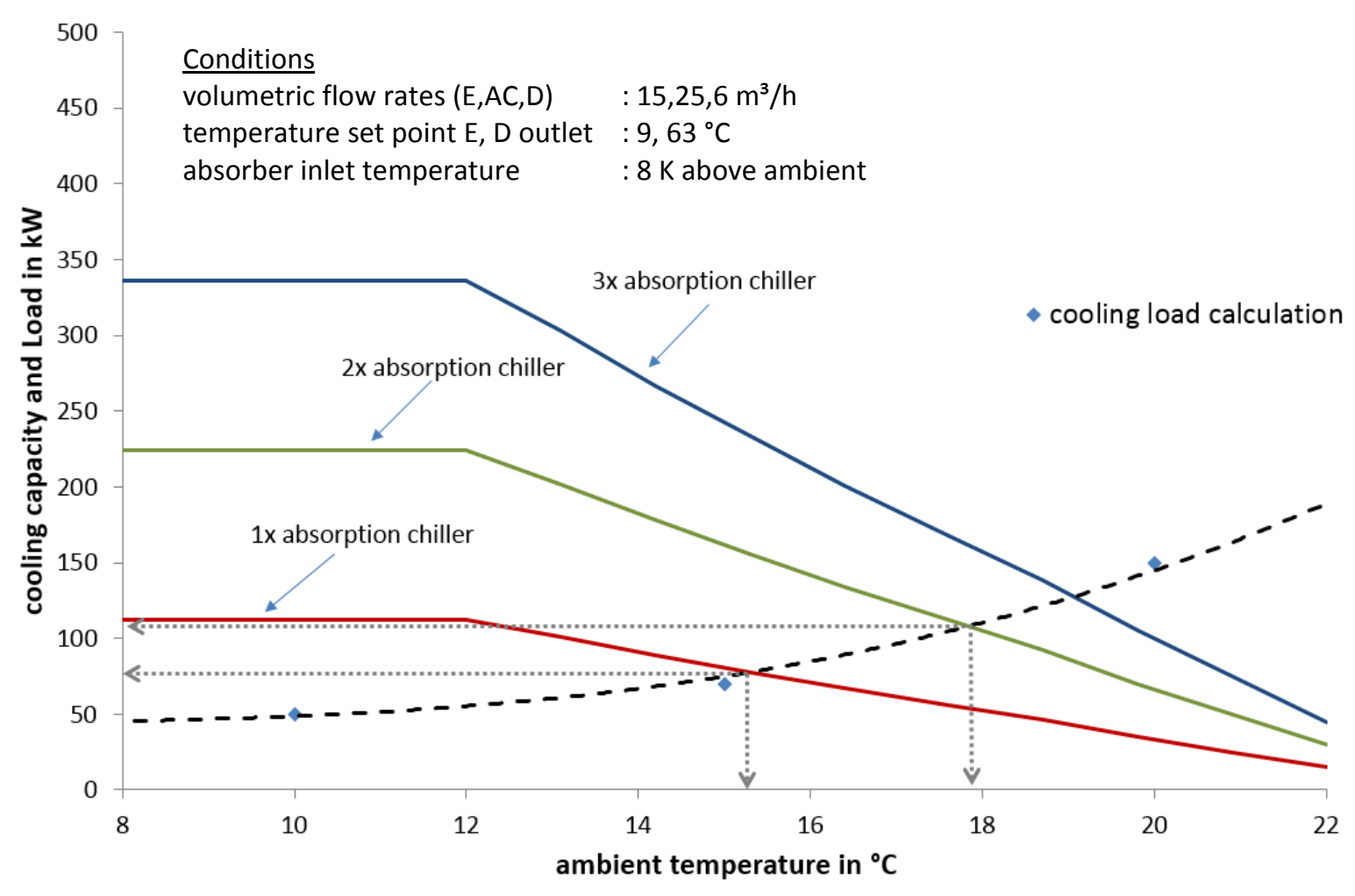

Figure 6. Cooling load and capacity as a function of the ambient temperature

The integrated load detection of each individual absorption chiller does not take into consideration other system components. Therefore, in order to optimize the system, a mastercontroller is required. Its logic takes into consideration additional information such as the conditions described in Figure 6 and the energy consumption of the reject heat device.

The resulting savings can be deduced from figure 7, which shows in the upper diagram the thermal $\mathrm{COP}_{\text {th }}$ and in the lower diagram the electrical $\mathrm{COP}_{\mathrm{el}}$ both as function of the cooling power provided. The master logic (green dots) increases the thermal $\mathrm{COP}_{\text {th }}$ and the electrical $\mathrm{COP}_{\text {el }}$ compared to the former operation with individual chiller control only (blue triangles).

The thermal $\mathrm{COP}_{\text {th }}$ increases because the internal processes are improved by avoiding part load conditions of the three chillers as much as possible - however, without reducing the $8 \mathrm{~K}$ temperature difference from the cooling water to the ambient. By this means, at an overall load of up to $140 \mathrm{~kW}$ the thermal $\mathrm{COP}_{\text {th }}$ is approximately $10 \%$ higher than operating without the master logic. At this load, all absorption chillers work at full load with a mean $\mathrm{COP}_{\text {th }}$ of $0.75 \mathrm{~kW}_{\text {th }} / \mathrm{kW}_{\text {th }}$ corresponding to the conditions in figure 6 ; above this load they operate with increased speed of the fan of the cooling tower.

Also the electrical $\mathrm{COP}_{\text {el }}$ can be improved whenever the system does not need to work at full capacity (lower graph of figure 7). Please note that here the reject heat device is not contained because it is shared with the backup compression chiller. Under these circumstances, the $\mathrm{COP}_{\mathrm{el}}$ is three times larger with master control than without up to a load of $100 \mathrm{~kW}$. Above this load, the improvement decreases but is still significant up to a load of about $200 \mathrm{~kW}$. 


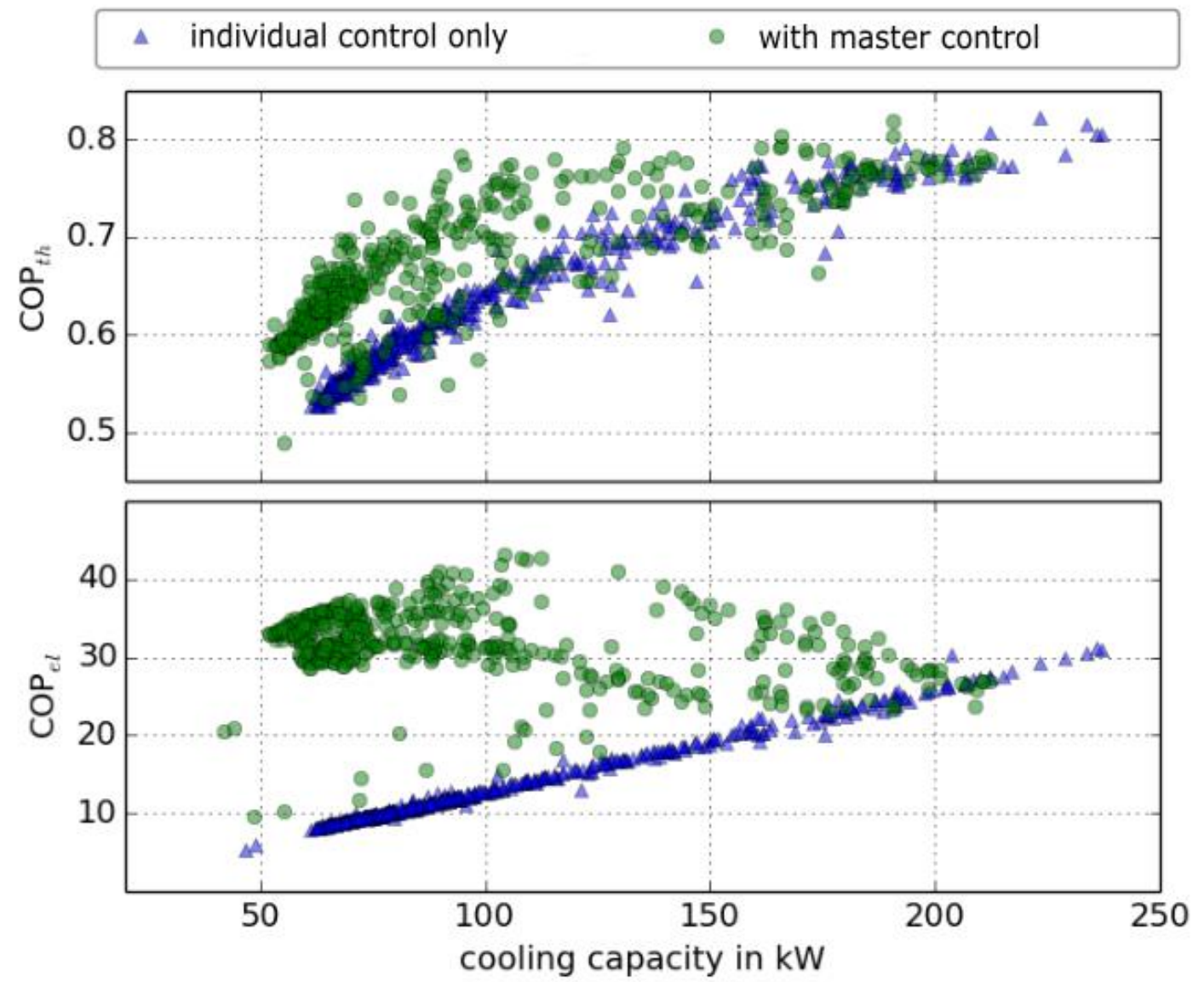

Fgure 7. Thermal and electrical coefficient of performance as function of the cooling capacity

\section{Conclusions}

The presented results indicate the potential of absorption chillers. The diversity of the operating conditions demonstrates the range of applications where heat of low exergetic value - waste heat or solar heat - can be used to produce cold for air-conditioning or cooling processes on the one hand, but also the need for a flexible and adjustable control and process on the other hand.

Most of the 27 chillers in 20 locations in operation worked until 2017 already for more than one cooling season. The chillers themselves have a high availability between $90-100 \%$ [8], defined as the ratio of failure-free operational time to requested time. A cooling load coverage from $70-90 \%$ depending on the installation was observed. The thermal coefficient of performance $\mathrm{COP}_{\text {th }}$ most of the time is between $0.7-0.8 \mathrm{~kW}$ th $/ \mathrm{kW}_{\text {th }}[6]$.

The demand of primary energy to produce one unit of cold mostly depends on the primary energy factor of the heat source. The official certified primary energy factor in 2016 [9] of the locations lays between 0 and $0.7 \mathrm{~kW}$ PE $/ \mathrm{kW}_{\text {heat. }}$. The primary energy consumption ${ }^{5}$ including electrical consumption and its primary energy factor varies between 0.7 and 0.1 $\mathrm{kW}$ PE $/ \mathrm{kW}_{\text {cold. }}$

\footnotetext{
${ }^{5}$ The primary energy consumption here is defined as the ratio between primary energy of every component related to the absorption chiller (pumps, reject heat device but also district heat) and the heat flow of evaporator.
} 
Thanks to their flexibility, the absorption chillers can operate with driving temperatures of 55 ${ }^{\circ} \mathrm{C}$ and deal with reject heat temperatures of up to $40{ }^{\circ} \mathrm{C}$ making the use of dry cooling towers feasible.

Prioritizing the control objectives enhances the overall system efficiency. Controlling not only the cooling capacity, but also the driving heat outlet temperature by active control of the reject heat temperature ensures stable operation with small cogeneration units. In decentralized systems, return temperatures of the driving heat down to $45-50^{\circ} \mathrm{C}$ and supply line temperatures down to $60^{\circ} \mathrm{C}$ enlarge the number of heat sources that can be used for the technology.

The focus of the actual ongoing investigations is on decreasing electric power consumption of peripheral components such as pumps and the reject heat systems to achieve at least an annual mean value below $5 \%$ of electric consumption in comparison to the cooling load which corresponds to an efficiency of $\mathrm{COP}_{\mathrm{el}}=20$. 


\section{Acknowledgement}

We would like to acknowledge all our partners within the presented projects: the German Association of District Heat and Energy Efficiency (AGFW), the Industry Association for Building Technology (BTGA), the TU Dresden and the ILK Dresden, and all field test partners. Moreover we gratefully acknowledge the funding by the Ministry of Environment of Jordan, the Deutsche Gesellschaft für internationale Zusammenarbeit (GIZ), the Bundesministerium für

Gefördert durch:

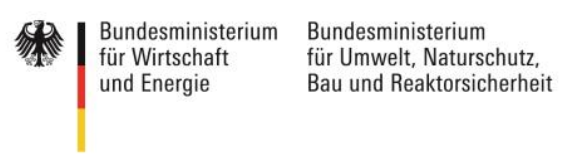

aufgrund eines Beschlusses des Deutschen Bundestages

Wirtschaft und Energie (BMWi), and the Bundesministerium für Umwelt, Naturschutz, Bau und Reaktorsicherheit.

\section{References}

1. IEA, Energy Technology Perspectives 2016: Towards Sustainable Urban Energy Systems, Organization for Economic Co-operation and Development (OECD), 2016.

2. Berliner Energieagentur $\mathrm{GmbH}$, Summerheat: Meet cooling needs in SUMMER by applying HEAT from cogeneration, Berlin, 2009.

3. BINE Information Service, Cooling with heat. A new generation of compact chillers cools and heats with low-temperature heat, Bonn, 07 2012. PDF < http://www.bine.info/fileadmin/content/Presse/Projektinfos_2012/Projekt_072012/ProjektInfo_0712_engl_internetx.pdf > last login : 27.02.2017

4. Albers, J. and Ziegler, F. Control Strategies for Absorption chillers in CHPC-plants ensuring low hot water return temperatures. Proc. of Heat powered cycle's conference. 2016.

5. Lunze, J. Regelungstechnik 2: Mehrgrößensysteme, Digitale Regelung (German Edition), Springer, 2010.

6. Lanser, W. Albers, J. Hüls, W. Paitazoglou, C. Hunt, S. Petersen, S. System Integration of Absorption Chillers: Initial Operating Experiences from an Field Test for CCHPSystems, in German, Conference: Tagungsband Deutsche Klima-Kälte-Tagung. Dresden, 2015.

7. Hennrich, C. Graf, R. Petersen, S. Absorption chillers connected to the return lines. Operating Experiences, in German, Conference: Tagungsband Deutsche Klima-KälteTagung. Kassel, 2016.

8. Paitazogou, C. Petersen, S. Schröder, M. Albers. J. Betriebsauswertung von Absorptionskälteanlagen im kleinen Leistungsbereich - Energieeffizienz von KWKKSystemen. Conference: Euro Heat \& Power, 2016.

9. List of primary energy factor FW 309-1 (German). Technical report, AGFW, Der Energieeffizienzverband für Wärme, Kälte und KWK e.V., 2016. 